|| ISSN(online): 2589-8698 || ISSN(print): 2589-868X ||

International Journal of Medical and Biomedical Studies

Available Online at www.ijmbs.info

NLM (National Library of Medicine ID: 101738825)

Index Copernicus Value 2019: 79.34

\title{
METAPLASTIC CARCINOMA OF BREAST
}

\author{
Dr. Lalit Aseri ${ }^{1}$, Dr. Vanita Kumar ${ }^{2}$, Dr. Sharda Dhawa ${ }^{3}$, Dr. Qadir Fatima ${ }^{4}$, Dr. Neelu Gupta ${ }^{2}$ \\ ${ }^{1}$ Post Graduate Resident, ${ }^{2}$ Senior Professor, ${ }^{3}$ Associate Professor, ${ }^{4}$ Senior Professor and Head \\ Department of Pathology, P.B.M Hospital, S.P Medical College, Bikaner
}

Article Info: Received 21 December 2020; Accepted 23 January 2021

DOI: https://doi.org/10.32553/ijmbs.v5i1.1678

Corresponding author: Dr. Lalit Aseri

Conflict of interest: No conflict of interest.

\begin{abstract}
Metaplastic carcinoma of the breast is a rare but aggressive type of breast cancer that has been recognized as a unique pathologic entity by the World Health Organization. Morphologically, it is characterized by the differentiation of neoplastic epithelium into squamous cells and/or mesenchymal-looking elements (spindle cells, cartilage or bone, etc). It shares many similarities with invasive ductal carcinoma and benign lesions on mammography, which further complicates the diagnosis. Treatment for metaplastic breast carcinoma is relatively unknown because of the rarity of the disease, but studies suggest that removal of the tumor and adjuvant radiation therapy has the greatest benefit.
\end{abstract}

\section{Introduction}

The 51 years old woman presented with approximately two months history of painful breast lump and axillary swelling.There is history of trauma two and half months before. No history of nipple discharging. There was no known family history of breast cancer. Palpation revealed a tender hard left breast lump in left upper quadrant and also a tender hard swelling at left axilla. Sonomammography of left breast and axilla revealed a hypoechoic mass of about $4.04 \times 3.12 \mathrm{~cm}$ in size with illdefined margin in the left breast and shows vascularity. In left axilla, there are few enlarged lymph nodes with no fat hilum. Size of one is about $1.64 \times 1.10 \mathrm{~cm}$.

In FNAC of lump revealed cellular smear shows sheets, fragments and clusters of ductal cells in between and around these clusters myoepithelial cells and bipolar cells seen. Few epithelial cells shows mild nuclear enlargement. Blood investigations were with in normal limits. Patient was nonreactive to HIV, HCV and HbsAg.

The patient was posted for surgery and left modified radical mastectomy was performed. Post operative period was uneventful. Gross specimen of mastectomy measuring $21 \times 14 \times 9 \mathrm{~cm}$ with axillary tail measuring 17x7 cm. Nipple areola was identified, which was retracted. No scar and ulceration seen on skin. On cut section an irregular greyish white growth measuring $7 \times 4 \times 3 \mathrm{~cm}$ identified, which was reaching upto nipple areola and $3 \mathrm{~cm}$ away from posterior margin. Four lymph nodes identified, Larger one measuring $3 \times 2 \times 1.5 \mathrm{~cm}$. (figure 1A-1B). Histological examination reveals squamous component showing islands of large polygonal cells and whorling with ductal component showing areas of pleomorphic hyperchromatic cells arranged in nests, cords, and papillary pattern. (figure 2A2E).
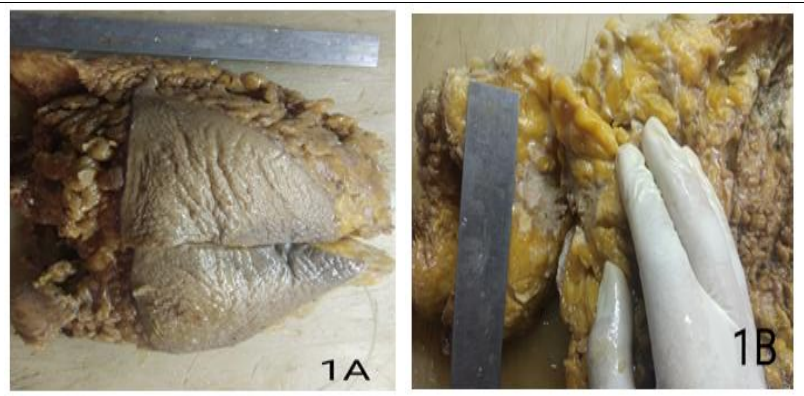

Figure 1: Gross appearance of specimen of Modified radical mastectomy $(\mathrm{A})$, an irregular greyish white growth is seen in left upper quadrant (B).
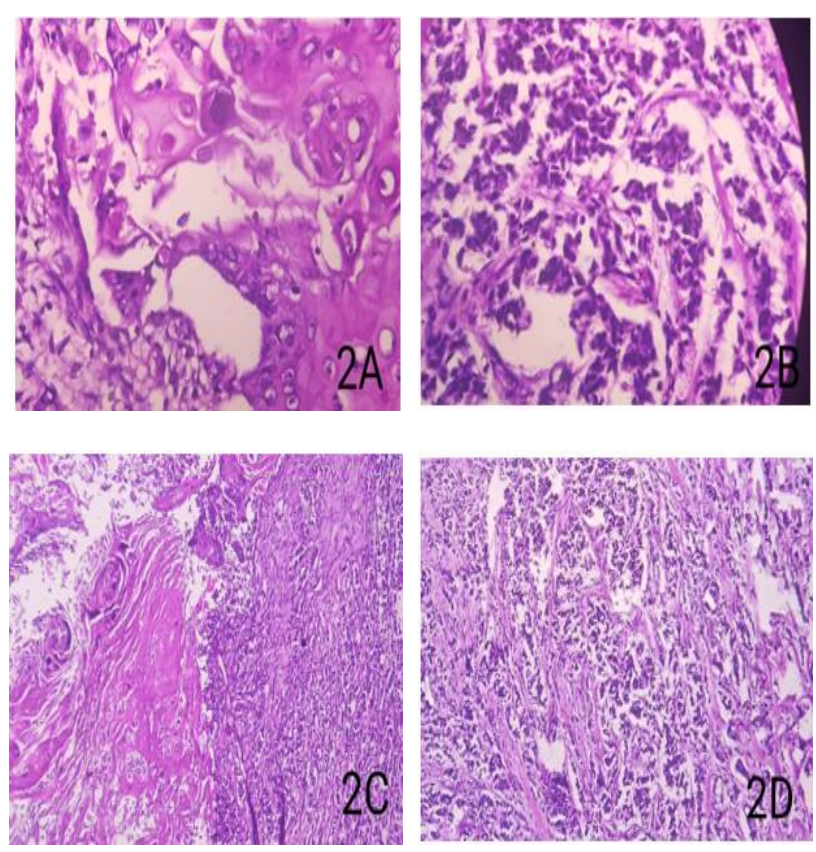


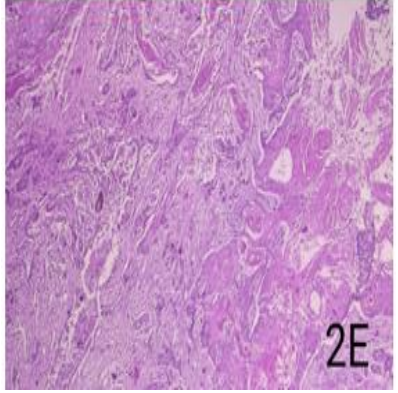

Figure 2: Squamous cell carcinoma at 40x (A), infiltrating ductal carcinoma at 40x(B), low power view showing both components $(\mathrm{C})$, infiltrating ductal carcinoma representing area of pleomorphic hyperchromatic cells arranged in nests, cords and papillary pattern at 10x (D), squamous component of breast showing islands of large polygonal cells and whorling at 10x (E).

\section{Discussion}

Metaplastic carcinomas are rare forms of invasive carcinomas of breast. Metaplastic carcinoma is a generic term for breast carcinoma of ductal type in which the predominant component of the neoplasm has an appearance other than glandular and epithelial and more in keeping with other cell type. It includes various categories:

- Sarcomatoid carcinoma, carcinosarcomas and matrix producing carcinomas

- Spindle cell carcinomas

- Carcinomas with osteoclast like giant cells

- Squamous cell carcinoma

- Melanocytic differentiation

- Choriocarcinomatous features

- Pleomorphic carcinomas. ${ }^{1}$

The mean patient age for metaplastic carcinomas of breast is 47.6 years. $^{2}$ Grossly, these tumors form large, firm, nodules having a median size of $5 \mathrm{~cm}$. Fixity to skin or deep fascia is not uncommon. ${ }^{3}$

The differential diagnosis of metaplastic carcinomas depends on the degree of atypia observed in the tumor and includes exuberant scars, fibromatosis, nodular fasciitis, myofibroblastomas, pseudoangiomatous stromal hyperplasia, acute and chronic abscess with fat necrosis, malignant phyllodes tumor and primary or metastatic sarcoma. ${ }^{4}$

Lymph node involvement is uncommon but was seen in both our cases. Hematogenous spread is common explained by sarcomatous element, leading to metastasis to lung, liver, brain and bone.

These tumors commonly reveal activation of the Wnt signaling pathway, epidermal growth factor receptor (EGFR) gene amplification and over-expression. ${ }^{4}$ Metaplastic carcinoma of the breast are characterized by ER/PR and Her2u negativity. When compared to triple- negative carcinomas, metaplastic carcinomas significantly more frequently expressed basal markers, such as CK14, CK17 and EGFR and over-express EGFR, vascular endothelial growth factor and caveolin-1, which can be used as therapeutic targets. ${ }^{2}$

A study by Lim et al. compared the clinical features and prognosis of triple negative metaplastic carcinomas and non-triple negative metaplastic carcinomas and concluded that non-triple negative metaplastic carcinomas had a poorer prognosis compared to triple negative patients. ${ }^{5}$

Similarly Bae et al. reviewed 47 metaplastic breast carcinoma and 1346 infiltrating duct carcinomas. They concluded that metaplastic carcinomas are associated with a larger tumor size, lower lymph node involvement, higher histological and nuclear grade, high triple negativity, higher p53, CK 5/6 and EGFR expression, worse prognosis with a disease free survival rate being $78.1 \%$ in metaplastic breast carcinomas compared to $91 \%$ in infiltrating duct carcinomas. $^{6}$

In general metaplastic carcinomas are triple negative and do not respond to transtuzumab. These tumors classically express HER1/EGFR, thus majority of metaplastic carcinomas are treated with EGFR inhibitors such as geftinib and cetuximab. ${ }^{7}$

\section{Conclusion}

Metaplastic carcinomas of the breast are rare but aggressive tumors. Early diagnosis is essential because they are triple negative, but over-express EGFR requiring a change in the therapeutic regime.

\section{Reference}

1. Rosai J. Breast. In: Rosai and Ackerman's Surgical Pathology. 10 th ed. USA: Elsevier Inc.; 2011. p. 1704-5.

2. Kim JY, Kim T, Dho EY. Comparative study of metaplastic breast carcinoma and triple negative breast carcinoma using histological and immunohistochemical analyses. Korean J Pathol 2010;44:605-12.

3. Ellis IO, Pinder SE, Lee AH. Tumors of the breast. In: Fletcher C, editor. Diagnostic Histopathology of Tumors. 3 rd ed. USA: Elsevier Limited; 2007. p. 938-9.

4. Rungta S, Kleer CG. Metaplastic carcinomas of the breast: Diagnostic challenges and new translational insights. Arch Pathol Lab Med 2012;136:896-900.

5. Lim KH, Oh DY, Chie EK, Han W, Im SA, Kim TY, et al. Metaplastic breast carcinoma: Clinicopathologic features and prognostic value of triple negativity. Jpn J Clin Oncol 2010;40:112-8

6. Bae SY, Lee SK, Koo MY, Hur SM, Choi MY, Cho DH, et al. The prognoses of metaplastic breast cancer patients compared to those of triple-negative breast cancer patients. Breast Cancer Res Treat 2011;126:471-8.

7. Esses KM, Hagmaier RM, Blanchard SA, Lazarchick JJ, Riker AI. Carcinosarcoma of the breast: Two case reports and review of the literature. Cases J 2009;2:15. 